\title{
CONSEQÜÊNCIAS DE DIFERENTES SISTEMAS DE PREPARO DO SOLO SOBRE DISTRIBUIÇÃO QUÍMICA E PERDAS DE FÓSFORO DE UM ARGISSOLO ${ }^{(1)}$
}

\author{
JOSE EZEQUIEL VILLAREAL NÚÑEZ ${ }^{(2)}$; NELSON MOURA BRASIL \\ DO AMARAL SOBRINHO ${ }^{(3,4)}$;NELSON MAZUR ${ }^{(3)}$
}

\begin{abstract}
RESUMO
O experimento foi realizado na microbacia de Caetés, município de Paty do Alferes (RJ), entre janeiro e março de 1997, no ciclo de cultivo do pepino (Cucumis sativus L.), em uma área de Argissolo Vermelho-Amarelo, latossólico textura argilo-arenosa/argilosa e declividade de 60\%, no qual foram instaladas parcelas de erosão do tipo Wischmeier. Os tratamentos utilizados foram os seguintes: (a) MAQ-aração com trator morro abaixo e queima dos restos vegetais; (b) MANQ-aração com trator morro abaixo não queimado com restos de vegetação natural entre as linhas; (c) AA-aração com tração animal em nível, faixas de capim colonião a cada 7,0 m e (d) CM-cultivo mínimo, roçado e coveamento. Nas linhas de plantio e nas covas, em cada parcela foram coletadas amostras de solo na camada arável, antes do plantio e depois da colheita. Após cada chuva que resultou em escoamento de sedimentos, o material nas caixas coletoras foi recolhido, seco, pesado e reservado para análises de: $\mathrm{P}$ total, lábil, orgânico e inorgânico, carbono orgânico e $\mathrm{pH}$ em água. O tratamento $\mathrm{CM}$ reduziu as perdas de $\mathrm{P}$ e influenciou na distribuição das formas lábil e orgânica de P. O tratamento MAQ perdeu de 12,4\% do P total adicionado, enquanto o CM perdeu apenas $1 \%$. A permanência dos restos de vegetação natural entre as linhas de plantio, na parcela MANQ, diminuiu em $40 \%$ a perda total de $\mathrm{P}$, com relação ao tratamento MAQ. As parcelas MAQ e MANQ mostraram um enriquecimento de argila nos sedimentos o que favoreceu a maior perda de P adsorvido nesta fração.
\end{abstract}

Palavras-chave: preparo de solo, fracionamento de fósforo, perdas por erosão.

\section{ABSTRACT \\ SOIL MANAGEMENT EFFECTS ON CHEMICAL DISTRIBUTION AND LOSSES OF PHOSPHORUS IN AN ULTISOL}

The research was accomplished in the Caetés watershed, municipal district of Paty do Alferes (RJ), from January to March of 1997, in the crop cycle of cucumber (Cucumis sativus L.). The research took place in an area of Yellow-Red Podzolic soil (Udult), of clayey texture, at a slope of $60 \%$, where Wischmeier plots for studying soil erosion were installed. The treatments applied were: (a) MAQ - down hill mechanical

( $\left.{ }^{1}\right)$ Parte da tese de mestrado do primeiro autor, apresentada ao Departamento de Solos da Universidade Federal Rural do Rio de Janeiro (UFRRJ), Seropédica (RJ). Pesquisa realizada com recursos da União Européia e Ciamb-PADCT/FINEP. Recebido para publicação em 29 de outubro de 2001 e aceito em 13 de janeiro de 2003.

$\left(^{2}\right)$ Instituto de Investigación Agropecuaria de Panamá (IDIAP), Apartado 58, Santiago, Província de Veraguas. E-mail:idiapdi@cerco.net

$\left(^{3}\right)$ Departamento de Solos da Universidade Federal Rural do Rio de Janeiro (UFRRJ), 23850-000 Seropédica (RJ). E-mail:nelmoura@ufrrj.br; nelmazur@ufrrj.br

$\left({ }^{4}\right)$ Com bolsa de produtividade científica do CNPq. 


\begin{abstract}
tillage, and burning of crop residues; (b) MANQ - contour mechanical tillage, with plant residues remaining on the field; (c) AA - contour tillage, with animal traction and strips of grasses placed every 7,0 m; and (d) CM - minimum tillage. Soil samples were collected in crop rows, and planting pits, in the plow layer, before planting and after harvesting. After each rain that resulted in production of sediments, the material was collected, dried, weighed, and kept for analyzes of total P; labile, organic and inorganic $\mathrm{P}$; organic carbon; and $\mathrm{pH}$ in water. The $\mathrm{CM}$ treatment reduced $\mathrm{P}$ losses and influenced the distribution of labile and organic forms of P. MAQ treatment implied in loss of $12.4 \%$ of the total applied P, while the CM lost only $1 \%$. The remaining of the plant residues among the crop rows, on the MANQ plot, decreased in $40 \%$ the total P loss, when compared to MAQ. The plots MAQ and MANQ showed clay increase in the sediments, which favored the highest losses of P sorbed in the clay fraction.
\end{abstract}

Key words: soil tillage, P fractionation, erosion losses.

\section{INTRODUÇÃO}

A erosão hídrica provoca perdas de solo, água e nutrientes, principalmente, daqueles que são adsorvidos na superfície das partículas de argila e matéria orgânica e constitui um dos fatores que mais contribui para a queda de produtividade do solo e a decadência de muitas lavouras (SILVA et al., 1997). A erosão é influenciada pelo regime hídrico, topografia do terreno, natureza do solo e práticas agrícolas (Moura Ferreira, 1986).

Um dos sistemas de preparo do solo mais tradicional no Brasil é a aração e gradagem através do uso de discos, o qual leva à degradação física do solo (De Maria e Castro, 1993). Uma das formas de diminuir a alteração da estrutura do solo é o uso do cultivo mínimo, que também contribuirá para o acúmulo de nutrientes na camada arável, menor quebra dos agregados e aumento da porosidade e infiltração da água, reduzindo as perdas por erosão (ISENSEE e SADEGUI, 1996).

Vários trabalhos têm demonstrado que a substituição do preparo convencional pelo cultivo mínimo reduziu as perdas por erosão, e aumentou a infiltração e a quantidade disponível de água e de nutrientes para as plantas (EDWARDS et al., 1988; DicK et al., 1989; IsENSEe e SADEgui, 1993).

O município de Paty do Alferes, localizado na região serrana do Estado do Rio de Janeiro, tem, exclusivamente, a agricultura como principal atividade econômica. Lá são produzidos cerca de $40 \%$ de todo o tomate do Estado do Rio de Janeiro e grande percentual de outras olerícolas, tais como: repolho, pepino, vagem, pimentão, etc.

Na última década, apesar dos altos investimentos, a produção agrícola vem decrescendo devido a problemas como utilização de práticas não adequadas às condições edafo-climáticas; realização de $90 \%$ das atividades agrícolas em encostas com declividade média de $45 \%$, e com preparo do solo feito morro abaixo, sem utilização de práticas conservacionistas, provocando a perda excessiva de solo e de nutrientes, especialmente, o fósforo o qual se acumula nos sedimentos, podendo provocar a eutrofização das águas através do crescimento de algas (NúNEEZ et al.,1999)

Segundo Resende et al. (1996), a principal forma de perda de fósforo em áreas agrícolas de alta declividade ocorre por efeito da erosão. A lixiviação de fósforo e, conseqüentemente, a contaminação do lençol freático é limitada devido a forte interação do fósforo com a superfície das partículas de solos intemperizados.

Os principais mecanismos de retenção de fósforo nesses solos, ricos em óxidos, oxi-hidróxidos e hidróxidos de $\mathrm{Fe}, \mathrm{Al}$ e Mn, é a adsorção específica através da formação de complexos de esfera interna e a precipitação com ferro e alumínio (SPOSITo, 1989).

Vários fatores influenciam na distribuição de fósforo nas suas formas orgânica e inorgânica, sendo que geralmente entre $50 \%$ e $90 \%$ do fósforo é inorgânico, consistindo de fosfatos de ferro e alumínio em solos ácidos, e fosfatos de cálcio em solos alcalinos (Sposito, 1989). O fósforo transportado pela erosão do ambiente terrestre para ambientes aquáticos pode estar tanto na forma solúvel como na oclusa. Como o fósforo é fortemente adsorvido pelas argilas, a maior proporção do fósforo transportado, pelas enxurradas, para os ambientes aquáticos, a partir de solos cultivados, ocorre na forma adsorvida (SHARPLEY E MENZEL, 1987)

Este trabalho teve como objetivos: (a) quantificar as perdas de $P$ por erosão influenciada pelo sistema de preparo do solo; e (b) determinar como os sistemas de preparo do solo influenciam na distribuição das formas químicas de $P$.

\section{MATERIAL E MÉTODOS}

Para a realização deste trabalho, utilizou-se de parcelas do tipo Wischmeier, instaladas em área da microbacia de Caetés, no município de Paty do Alferes-RJ, em 1997, a fim de avaliar as perdas de solo causadas pelas chuvas. 
A cultura, pepino (Cucumis sativus L.), foi implantada em dezembro de 1996, e os insumos agrícolas utilizados e as quantidades aplicadas no experimento foram as seguintes: esterco de curral $\left(40 \mathrm{t}^{-h a^{-1}}\right)$, torta de manona (2 t.ha $\left.{ }^{-1}\right)$, Termofosfato de Yoorin $\left(800 \mathrm{~kg} \cdot \mathrm{ha}^{-1}\right), \quad \mathrm{KCl} \quad\left(140 \mathrm{~kg} \cdot \mathrm{ha}^{-1}\right), \quad\left(\mathrm{NH}_{4}\right)_{2} \quad \mathrm{SO}_{4}$ $\left(140 \mathrm{~kg} \cdot \mathrm{ha}^{-1}\right)$ aplicado $50 \%$ no plantio, e o restante 30 dias após. As adubações e os controles fitossanitários foram os mesmos em todos os tratamentos. As parcelas estavam localizadas em uma área de Argissolo Vermelho-Amarelo latossólico, textura argila arenosa/ argilosa, típica da região, com uma declividade em torno de $60 \%$.

Foram utilizados os sistemas de preparo de solo: (a) MAQ: aração com trator morro abaixo e restos vegetais queimados (preparo típico da região); (b) MANQ: aração com trator morro abaixo e restos vegetais não queimados; (c) AA: aração com tração animal em nível, faixas de capim colonião a cada $7 \mathrm{~m}$, e (d) CM: cultivo mínimo com preparação de covas em nível, em um delineamento experimental em blocos ao acaso, com quatro repetições totalizando 16 unidades experimentais (parcelas). Os tratamentos são designados pelas siglas correspondentes aos sistemas de preparo de solo.

Coletaram-se, em todos os tratamentos, nas entrelinhas e nas covas, antes do plantio e depois da colheita, 20 amostras simples para formar uma amostra composta de solo da camada arável $(0-20 \mathrm{~cm})$.

O solo perdido por erosão foi armazenado em dois tanques coletores, conectados em série, e instalados no fim de cada parcela. Após cada chuva, a suspensão de solo armazenada foi homogeneizada, o volume anotado, e uma alíquota de volume conhecido foi coletada, seca em estufa com circulação de ar forçada a $60^{\circ} \mathrm{C}$, o solo pesado e a quantidade, perdida por erosão, calculada.

Ao fim do ciclo do pepino, as amostras de cada parcela, coletadas após cada chuva, foram misturadas em quantidades proporcionais às perdas totais calculadas no período, obtendo-se uma amostra composta de material perdido por erosão por parcela.

Após a secagem, as amostras de solo coletadas e as amostras de solo perdidas por erosão foram destorroadas, homogeneizadas e passadas através de uma peneira de $2 \mathrm{~mm}$, sendo em seguida trituradas em almofariz de ágata e guardadas em sacos de plástico para análise.

Nas amostras de solo coletadas e naquelas do solo perdido por erosão, dos quatro tratamentos, determinou-se o teor total de fósforo, por digestão nitro-perclórica, utilizando bloco de digestão e mistura de $\mathrm{HNO}_{3}+\mathrm{HClO}_{4}$ (TEDEsCO et al., 1997).
Foi também realizada a extração seqüencial de P, nas amostras de solo e de sedimentos, utilizando-se o procedimento desenvolvido por BOWMAN (1989) e descrito na figura 1, para determinar a distribuição do $\mathrm{P}$ nas formas orgânicas $\mathrm{e}$ inorgânicas. A fração lábil do $\mathrm{P}$ foi determinada através da extração com solução de Mehlich-1 (EMBRAPA, 1997).

Analisou-se o carbono orgânico pelo método da digestão úmida de Walkley \& Black (EMBRAPA, 1997). A análise granulométrica nas amostras de solo coletadas e no solo perdido por erosão foi realizada utilizando o método da pipeta (EMBRAPA, 1997).

As análises estatísticas foram realizadas com o auxílio do Programa Estatístico SAEG 5.0. O procedimento adotado para comparação de médias foi o teste Tukey, ao nível de 5\%.

\section{RESULTADOS E DISCUSSÃO}

O quadro 1 apresenta as formas e o teor total de fósforo dos solos, amostrados nas diferentes parcelas, antes do plantio e depois da colheita.

Verifica-se na parcela sob cultivo mínimo os teores mais elevados de $\mathrm{P}$ total, tanto nas entrelinhas como nas covas das parcelas, o que demonstra, claramente, que esse sistema de cultivo ao reduzir as perdas de solo por erosão (Figura 2) também favoreceu a acumulação de fósforo. Observa-se também no Quadro 1, que o sistema de preparo influenciou na distribuição do $\mathrm{P}$ lábil e nas formas orgânicas e inorgânicas de fósforo.

Quantidades mais elevadas de P lábil foram verificadas no $\mathrm{CM}$ quando comparado com os outros sistemas, onde o solo foi mais revolvido, favorecendo, provavelmente, uma maior disponibilidade desse nutriente.

Os sistemas de cultivo em que o solo recebe o mínimo de preparo podem apresentar acúmulo de nutrientes disponíveis às culturas nas camadas mais superficiais, especialmente de elementos com movimentação reduzida no perfil como o fósforo (DE MARIA e CAstro, 1993; Muzilli, 1983; Centurion et al., 1985).

Os Argissolos são solos que apresentam um horizonte $\mathrm{B}_{\mathrm{t}}$ com acúmulo de argila que, nesse caso, compõe-se principalmente de caulinita e óxidos de ferro e alumínio (NúÑEZ et al,1999), os quais possuem sítios específicos de adsorção de P.

O maior revolvimento do solo aumentará a superfície de contato dos horizontes subsuperficiais com os fosfatos solúveis aumentando a fixação das formas mais lábeis desse elemento. 


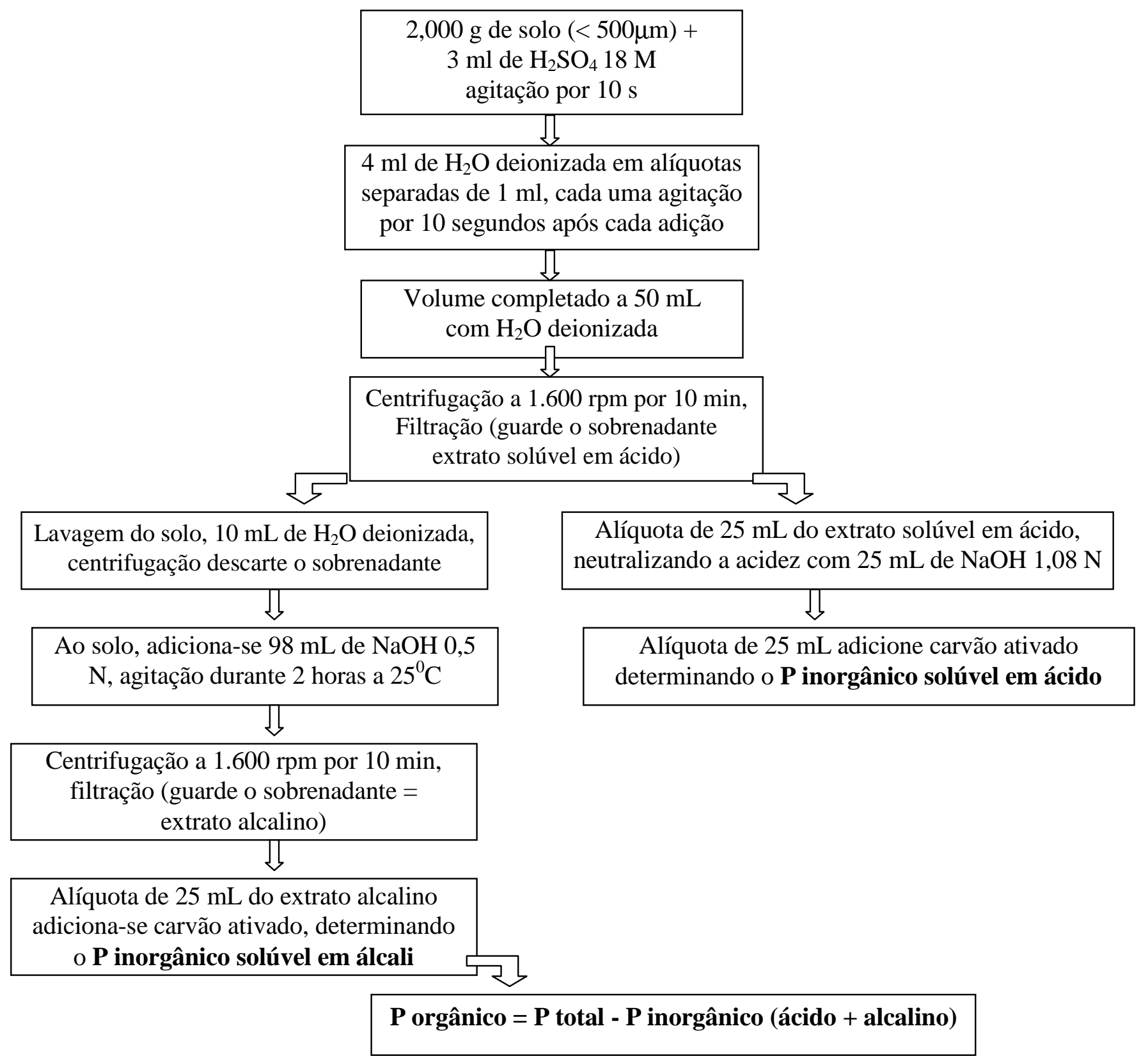

Figura 1. Esquema de fracionamento de P desenvolvido por Bowman (1989).

Nesse sentido, Novais et al. (1985) mostraram que quanto maior o revolvimento do solo, maior será a adsorção do fósforo, provocando aumento na velocidade das transformações do P lábil para formas não lábeis. $\mathrm{O}$ fósforo inorgânico, em todos os tratamentos, representou quase $70 \%$ do total; o fósforo orgânico, em torno de $29 \%$ e o lábil correspondeu a aproximadamente $28 \%$ das amostras coletadas nas entrelinhas e $30 \%$ nas covas no solo das parcelas sob CM.
Entretanto, verificou-se menor percentagem $(14 \%$ e $8 \%)$ dessa fração mais disponível, no sistema de cultivo MAQ, típico da região.

Verificou-se, também, diminuição nas percentagens de fósforo orgânico, nas amostras coletadas após a colheita, nos três sistemas de cultivo mais tradicionais, porém no $\mathrm{CM}$ foi mantida em torno de $28 \%$, demonstrando o efeito da matéria orgânica do solo sobre essa fração. 


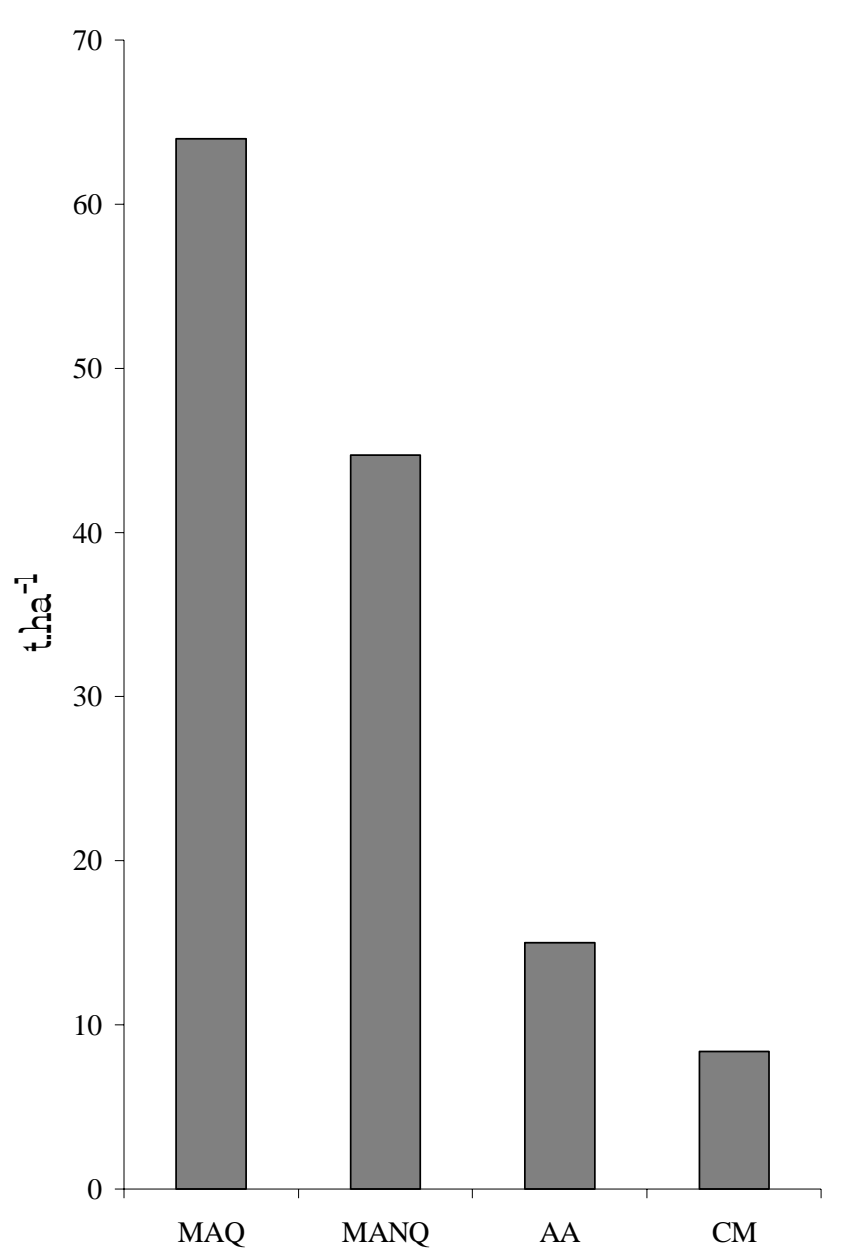

Figura 2. Perda de solo por erosão (t.ha $\left.{ }^{-1}\right)$ em função do sistema de preparo do solo no ciclo de cultivo do pepino (Cucumis sativus L.).

No cultivo mínimo, os resíduos de cultura são aproveitados deixando-os sobre a superfície do solo, favorecendo o acúmulo de matéria orgânica e conseqüentemente de P orgânico. Segundo SILVA E VIDOR (1984), quanto menor for o preparo dado ao solo, maior será o acúmulo de resíduos orgânicos na superfície, promovendo o acúmulo de matéria orgânica, como se verifica no quadro 2. Grande parte desses resíduos é rico em $\mathrm{P}$, sua decomposição e posterior mineralização do P orgânico, provavelmente, forneceria $\mathrm{P}$ inorgânico para a reassimilação microbiana, absorção vegetal e reação com os componentes minerais. Segundo GuERra (1993), o P orgânico seria estabilizado junto à matéria orgânica ou poderia interagir com os componentes minerais do solo.

As frações lábil e inorgânica, depois da colheita, demonstraram um ligeiro aumento, provavelmente, devido à mineralização e à liberação do P orgânico do solo em todos os preparos.
Correlações realizadas com os resultados das análises das amostras coletadas depois da colheita, revelaram que o P lábil mostrou uma correlação altamente significativa $\left(\mathrm{r}=0,98^{* *}\right)$, com o $\mathrm{P}$ inorgânico e com o P orgânico $\left(\mathrm{r}=0,96^{* *}\right)$, demonstrando a contribuição da forma orgânica de $\mathrm{P}$ na disponibilidade para as plantas. Segundo GUERRA ET AL. (1996), em solos altamente intemperizados as frações lábeis de $\mathrm{P}$ estão intimamente ligadas com as frações orgânicas, representando o P-orgânico a mais importante reserva de P lábil para as plantas.

No quadro 2 consta a concentração de matéria orgânica no solo, antes do plantio e depois da colheita, em cada um dos quatro sistemas de preparo e, também, a quantidade perdida por erosão $\left(\mathrm{kg} . \mathrm{ha}^{-1}\right)$ no ciclo de cultivo do pepino. Pode-se observar que os teores de matéria orgânica nos tratamentos MAQ, MANQ e AA foram significativamente inferiores quando comparados ao tratamento CM, caracterizando, claramente, a contribuição do cultivo mínimo na manutenção da matéria orgânica do solo. Segundo BAyer e Mielniczuk (1997), a alta intensidade de revolvimento do solo influencia tanto os regimes de aeração, umidade e temperatura quanto na ruptura de agregados, exposição da superfície, fracionamento e incorporação dos resíduos culturais.

Os métodos de preparo do solo afetaram, provavelmente, a taxa de acumulação de matéria orgânica tanto pelas perdas por erosão como pela mineralização. Resultados semelhantes foram encontrados por De Maria e CAstro (1993), que também verificaram teores de matéria orgânica menores nos tratamentos em que envolvia maior intensidade de revolvimento do solo.

A perda por erosão de matéria orgânica nos tratamentos MAQ e MANQ foi cerca de três a seis vezes maior quando comparados aos tratamentos AA e CM respectivamente.

$\mathrm{O}$ quadro 3 apresenta as perdas de $\mathrm{P}$ por erosão, nas diferentes formas químicas, nos quatro sistemas de preparo do solo

Verifica-se que a quantidade total de $\mathrm{P}_{2} \mathrm{O}_{5}$ perdida por erosão no $\mathrm{CM}$ é bem inferior do que nos outros três sistemas de preparo. No tratamento MAQ as perdas de $\mathrm{P}_{2} \mathrm{O}_{5}$ foram cerca de 12 vezes maior que no CM. Esses resultados também demonstram que a simples permanência de vegetação nas entrelinhas, o tratamento MANQ, reduziu as perdas totais de P em $36 \%$ quando comparado ao sistema típico da região (MAQ). Resultados semelhantes foram encontrados em vários trabalhos (MuZILLI,1983; CENTURION et al., 1985; BAYER e MiELNICZUK, 1997), que também verificaram que o método de preparo do solo afetava a quantidade de $\mathrm{P}_{2} \mathrm{O}_{5}$ perdido por erosão. 
Quadro 1. Teor de P lábil e fracionamento de P nas formas orgânicas e mineral do solo nos tratamentos antes do plantio e depois da colheita

\begin{tabular}{|c|c|c|c|c|}
\hline Preparo do solo & P lábil & $\mathrm{P}$ inorgânico & P orgânico & P total \\
\hline
\end{tabular}

\section{ENTRELINHAS}

\begin{tabular}{|c|c|c|c|c|}
\hline \multirow[b]{2}{*}{$\mathrm{MAQ}^{(1)}$} & & & & \\
\hline & $33,3(14,6) b^{(2)}$ & $161,8(71,0) b$ & $66,2(29,0) b$ & $228,1 \mathrm{c}$ \\
\hline MANQ & $38,8(14,8) \mathrm{b}$ & $185,0(70,7) a$ & $76,7(29,3) \mathrm{a}$ & $261,8 b$ \\
\hline $\mathrm{AA}$ & $39,6(18,6) b$ & $151,1(70,9) b$ & $62,0(29,1) \mathrm{c}$ & $213,1 d$ \\
\hline \multirow[t]{2}{*}{$\mathrm{CM}$} & $78,8(28,9) a$ & $193,2(70,8) a$ & $79,7(29,2) \mathrm{a}$ & $268,6^{\mathrm{a}}$ \\
\hline & \multicolumn{4}{|c|}{ Depois da colheita } \\
\hline MAQ & $27,0(14,6) b$ & $145,8(78,9) \mathrm{c}$ & $39,0(21,1) \mathrm{d}$ & $184,8 \mathrm{c}$ \\
\hline MANQ & $27,0(12,4) b$ & $166,8(76,4) b$ & $51,5(23,6) b$ & $218,2 b$ \\
\hline AA & $27,7(15,0) b$ & $140,5(76,2) \mathrm{d}$ & $43,9(23,8) c$ & $184,4 \mathrm{c}$ \\
\hline \multirow[t]{3}{*}{$\mathrm{CM}$} & $76,9(30,9) a$ & $179,2(71,9) a$ & $70,4(28,3) a$ & $249,6^{\mathrm{a}}$ \\
\hline & \multicolumn{4}{|c|}{ COVAS } \\
\hline & \multicolumn{4}{|c|}{ Antes do plantio } \\
\hline MAQ & $42,4(8,0) \mathrm{c}$ & $357,9(70,9) \mathrm{d}$ & $146,8(29,1) b$ & $504,7 \mathrm{~b}$ \\
\hline MANQ & $48,1(9,0) \mathrm{C}$ & $379,2(70,9) b$ & $155,3(29,1) a b$ & $534,6^{\mathrm{a}}$ \\
\hline $\mathrm{AA}$ & $79,8(15,2) b$ & $370,7(70,0) \mathrm{c}$ & $151,4(29,0) a b$ & $522,2 \mathrm{ab}$ \\
\hline \multirow[t]{2}{*}{$\mathrm{CM}$} & $121,8(22,1) \mathrm{a}$ & $390,3(70,7) \mathrm{a} 0$ & $161,7(29,3) a$ & $552,1^{\mathrm{a}}$ \\
\hline & \multicolumn{4}{|c|}{ Depois da colheita } \\
\hline MAQ & $44,6(10,1) \mathrm{c}$ & $347,8(78,6) \mathrm{c}$ & $94,7(21,4) \mathrm{d}$ & $442,5 d$ \\
\hline MANQ & $47,3(10,2) \mathrm{c}$ & $347,8(75,4) \mathrm{c}$ & $113,4(24,6) \mathrm{c}$ & $461,3 c$ \\
\hline $\mathrm{AA}$ & $77,1(15,9) b$ & $357,7(73,6) b$ & $128,3(26,4) b$ & $486,0 \mathrm{~b}$ \\
\hline $\mathrm{CM}$ & $110,8(21,6) \mathrm{a}$ & $369,0(71,6) \mathrm{a}$ & $146,4(28,4) \mathrm{a}$ & $515,3^{\mathrm{a}}$ \\
\hline
\end{tabular}

Antes do plantio

$\left({ }^{1}\right)$ MAQ: aração com trator morro abaixo e restos vegetais queimados;MANQ: aração com trator morro abaixo e restos vegetais não queimados; AA: aração com tração animal em nível, faixas de capim colonião a cada $7 \mathrm{~m}$.

CM: cultivo mínimo com preparação de covas em nível.

$\left({ }^{2}\right)$ Os números entre parênteses indicam a percentagem que representa em relação ao $\mathrm{P}$ total.

Médias seguidas da mesma letra, nas colunas de amostras coletadas no mesmo local e época, para cada forma química de fósforo, não diferem ao nível de $5 \%$ pelo teste de Tukey.

A composição granulométrica do solo antes do plantio e no material perdido por erosão nos quatro sistemas de preparo é apresentada no quadro 4 . Verifica-se no material perdido por erosão redução da fração argila, com conseqüente aumento da fração areia, quando comparado com amostras retiradas antes do plantio. Resultados semelhantes foram encontrados por MARTins FilHo e Silva (1985), avaliando a composição granulométrica do material de solo perdido por erosão em Latossolo Vermelho-Amarelo distrófico, em Ubajara (CE). Esses autores verificaram que as principais frações perdidas por erosão nesses solos corresponderam à fração silte e areia.
Tais resultados poderiam explicar, em parte, a menor concentração de fósforo no material perdido por erosão, em vista da alta afinidade desse elemento pela fração argila (Sposito, 1989).

O tratamento MAQ, por causar maior revolvimento do solo (CARVALHO et al. 1997), apresentou um teor mais elevado da fração argila, quando comparado com os outros tratamentos, contribuindo, dessa forma, para maior perda por erosão do fósforo que interage fortemente com a superfície de óxidos, oxi-hidróxidos, hidróxidos e caulinita presentes nessa fração granulométrica do solo. 
Quadro 2. Teores no solo e perdas de matéria orgânica por erosão em função do sistema de preparo $\left({ }^{1}\right)$

\begin{tabular}{|c|c|c|c|c|c|}
\hline \multirow{2}{*}{ Preparo do solo } & \multicolumn{4}{|c|}{ Teor de matéria orgânica } & \multirow{2}{*}{$\begin{array}{c}\text { Perda } \\
\text { por erosão }\end{array}$} \\
\hline & Entrelinhas $\left({ }^{2}\right)$ & Entrelinhas $\left({ }^{3}\right)$ & Covas $\left({ }^{2}\right)$ & Covas $\left(\left(^{3}\right)\right.$ & \\
\hline & \multicolumn{4}{|c|}{ g. $\mathrm{kg}^{-1}$} & kg.ha-1 \\
\hline MAQ & $26,7 \mathrm{~b}$ & $25,2 b$ & $28,8 \mathrm{~b}$ & $23,6 b$ & $1.543 a$ \\
\hline MANQ & $24,5 b$ & $24,1 b$ & $24,1 b$ & $17,9 \mathrm{c}$ & $1.465 b$ \\
\hline $\mathrm{AA}$ & $28,3 b$ & $25,0 b$ & $30,0 \mathrm{~b}$ & $26,9 a$ & $536 c$ \\
\hline $\mathrm{CM}$ & $42,2 a$ & $35,3 a$ & $42,2 \mathrm{a}$ & $29,8 \mathrm{a}$ & $269 d$ \\
\hline
\end{tabular}

(') MAQ: aração com trator morro abaixo e restos vegetais queimados; MANQ: aração com trator morro abaixo e restos vegetais não queimados; AA: aração com tração animal em nível, faixas de capim colonião a cada $7 \mathrm{~m}$;

CM: cultivo mínimo com preparação de covas em nível.

$\left({ }^{2}\right)$ Antes do plantio.

$\left({ }^{3}\right)$ Depois da colheita.

Médias seguidas da mesma letra nas colunas não diferem ao nível de 5\% pelo teste de Tukey

Quadro 3. Perda de fósforo, na forma lábil e nas diferentes formas orgânicas e inorgânicas de $\mathrm{P}_{2} \mathrm{O}_{5}$ em função do sistema de preparo do solo no ciclo de cultivo do pepino

\begin{tabular}{|c|c|c|c|c|}
\hline \multirow{2}{*}{ Preparo do solo } & \multicolumn{4}{|c|}{$\mathrm{P}_{2} \mathrm{O}_{5}$} \\
\hline & Lábil & Inorgânico & Orgânico & Total \\
\hline & \multicolumn{4}{|c|}{ kg.ha ${ }^{-1}$} \\
\hline $\mathrm{MAQ}^{(1)}$ & $8,8(10,3)^{(2)} \mathrm{aD}$ & $52,2(62,0)$ aB & $31,9(37,8) \mathrm{aC}$ & $84,1 \mathrm{aA}$ \\
\hline MANQ & $5,9(11,1) b D$ & $33,7(62,8) b B$ & $19,9(37,2) b C$ & $53,6 \mathrm{bA}$ \\
\hline $\mathrm{AA}$ & $2,3(11,4) \mathrm{cD}$ & $13,2(65,9) \mathrm{cB}$ & $6,9(34,1) \mathrm{cC}$ & $20,1 \mathrm{cA}$ \\
\hline $\mathrm{CM}$ & $0,9(13,0) \mathrm{dD}$ & $4,8(70,0) \mathrm{dB}$ & $2,1(30,0) \mathrm{dC}$ & $6,9 \mathrm{dA}$ \\
\hline
\end{tabular}

(1) MAQ: aração com trator morro abaixo e restos vegetais queimados; MANQ: aração com trator morro abaixo e restos vegetais não queimados; AA: aração com tração animal em nível, faixas de capim colonião a cada $7 \mathrm{~m}$;

CM: cultivo mínimo com preparação de covas em nível.

$\left({ }^{2}\right)$ Os números entre parênteses mostram a percentagem que representa cada fração com relação ao $\mathrm{P}_{2} \mathrm{O}_{5}$ total.

Médias seguidas da mesma letra minúscula na coluna, e maiúscula, na linha, não diferem entre si pelo teste de Tukey (5\%).

Quadro 4. Composição granulométrica do solo antes do plantio e no material perdido por erosão nos quatro sistemas de preparo. Média de 3 repetições

\begin{tabular}{|c|c|c|c|c|c|c|c|c|}
\hline \multirow{2}{*}{$\begin{array}{l}\text { Preparo } \\
\text { do solo }\end{array}$} & \multicolumn{2}{|c|}{ Areia total } & \multicolumn{2}{|c|}{ Areia grossa } & \multicolumn{2}{|c|}{ Silte } & \multicolumn{2}{|c|}{ Argila total } \\
\hline & $\mathrm{AP}$ & Er & $\mathrm{AP}$ & Er & $\mathrm{AP}$ & Er & $\mathrm{AP}$ & Er \\
\hline & & & & 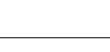 & & & & \\
\hline MAQ $\left(^{1}\right)$ & $500 \mathrm{aB}$ & $600 \mathrm{aA}$ & $130 \mathrm{aA}$ & $110 \mathrm{aA}$ & $100 \mathrm{aA}$ & $30 \mathrm{bB}$ & $400 \mathrm{bA}$ & $370 \mathrm{aB}$ \\
\hline MANQ & $460 \mathrm{bB}$ & $600 \mathrm{aA}$ & $140 \mathrm{aA}$ & $120 \mathrm{aA}$ & $100 \mathrm{aA}$ & $60 \mathrm{aB}$ & $440 \mathrm{aA}$ & $340 \mathrm{bB}$ \\
\hline AA & $480 \mathrm{bB}$ & $600 \mathrm{aA}$ & $140 \mathrm{aA}$ & $130 \mathrm{aA}$ & $110 \mathrm{aA}$ & $50 \mathrm{aB}$ & $410 \mathrm{bA}$ & $350 \mathrm{bB}$ \\
\hline CM & $480 \mathrm{bB}$ & $660 \mathrm{aA}$ & $130 \mathrm{aA}$ & $80 \mathrm{bB}$ & $120 \mathrm{aA}$ & $50 \mathrm{aB}$ & $400 \mathrm{bA}$ & $290 \mathrm{cB}$ \\
\hline
\end{tabular}

Médias seguidas da mesma letra maiúscula, na linha, e letra minúscula, na coluna, para cada fração granulométrica, não diferem entre si pelo teste de Tukey (5\%).

$\left({ }^{1}\right)$ MAQ: aração com trator morro abaixo e restos vegetais queimados; MANQ: aração com trator morro abaixo e restos vegetais não queimados; AA: aração com tração animal em nível, faixas de capim colonião a cada $7 \mathrm{~m}$.

CM: cultivo mínimo com preparação de covas em nível.

AP: teor no solo antes do plantio.

Er: teor no material de solo perdido por erosão. 
Quadro 5. Quantidade de $\mathrm{P}_{2} \mathrm{O}_{5}$ perdida por erosão equivalente em fertilizantes comerciais $\left(^{1}\right)$

\begin{tabular}{|c|c|c|c|}
\hline Preparo do solo & SPS & $\mathrm{SPT}$ & T. Yoorin \\
\hline & \multicolumn{3}{|c|}{ kg.ha-1 } \\
\hline MAQ $^{(2)}$ & 217,5 & 94,6 & 220,8 \\
\hline MANQ & 150,0 & 65,1 & 153,0 \\
\hline AA & 57,5 & 25,0 & 58,4 \\
\hline $\mathrm{CM}$ & 22,5 & 9,8 & 22,8 \\
\hline
\end{tabular}

$\left({ }^{1}\right)$ Quantidades calculadas a partir de $\mathrm{P}_{2} \mathrm{O}_{5}$ lábil e considerando-se uma concentração média de $\mathrm{P}_{2} \mathrm{O}_{5}$ solúvel de $20 \%$ no SPS (superfosfato simples), $46 \%$ no SPT (superfosfato triplo) e 19,7\% no T. Yoorin (Termofosfato de Yoorin) e uma eficiência média de $20 \%$ na adubação fosfatada (AzAmbuja, 1996)

$\left({ }^{2}\right)$ MAQ: aração com trator morro abaixo e restos vegetais queimados; MANQ: aração com trator morro abaixo e restos vegetais não queimados; AA: aração com tração animal em nível, faixas de capim colonião a cada 7 m; CM: cultivo mínimo com preparação de covas em nível.

O quadro 5 mostra a quantidade total de $\mathrm{P}_{2} \mathrm{O}_{5}$ perdida por erosão, equivalente em fertilizantes fosfatados comerciais, tradicionalmente, utilizados na microbacia. Constata-se maior eficiência do tratamento $\mathrm{CM}$ na conservação do $\mathrm{P}_{2} \mathrm{O}_{5}$ aplicado ao solo, ao reduzir as perdas de $P$ por erosão.

O segundo sistema de preparo de maior eficiência foi o AA, demonstrando que a menor alteração da estrutura do solo e o uso de barreiras naturais são práticas agrícolas eficientes para conservação do solo e manutenção da sua fertilidade.

Esses resultados demonstram, inequivocamente, que o sistema MAQ, típico da região, traz grandes prejuízos financeiros aos agricultores da microbacia e elevado impacto ambiental, com sérios riscos de eutrofização das águas.

Portanto, é um sinal de alerta para mudanças urgentes nas práticas de preparo do solo para uma maior proteção dos corpos d'água da microbacia e maiores lucros para os agricultores.

\section{CONCLUSÕES}

1. O cultivo mínimo (CM) mostrou ser o método de preparo do solo mais eficiente diminuindo, significativamente as perdas de solo e P por erosão. Práticas agrícolas simples e baratas como a utilização de faixas de vegetação permanente, com grama nativa nas entrelinhas das parcelas, também demonstraram ser métodos efetivos para reduzir as perdas de solo.

2. Os métodos de preparo do solo morro abaixo favoreceram um enriquecimento maior de argila nos sedimentos que o cultivo mínimo (CM) e aração com tração animal (AA) o que favoreceu a maior perda de fósforo.
3. O cultivo mínimo (CM) demonstrou claro efeito na distribuição das formas químicas de $\mathrm{P}$, favorecendo especialmente o acúmulo das frações de $\mathrm{P}$ lábil e orgânico no solo.

\section{REFERÊNCIAS BIBLIOGRÁFICAS}

AZAMBUJA, J.M.V. O solo e o clima na produtividade agrícola. Guaíba: Livraria e Editora Agropecuária, 1996. 164p.

BAYER, C.; MIELNICZUK, J. Características químicas do solo afetadas por métodos de preparo e sistemas de cultura. Revista Brasileira de Ciência do Solo, Campinas, v. 21, p.105-112,1997.

BOWMAN, R.A. A sequential extraction procedure with concentrated sulfuric acid and dilute base for soil organic phosphorus. Soil Science Society American Journal, Madison, v. 53, p.362-366, 1989.

CARVALHO, M.P.; CATANEO, A.; LOMBARDI NETO, F. Parâmetros de erosividade da chuva e da enxurrada correlacionados com as perdas de solo e determinação da erodibilidade de um podzólico vermelho-amarelo de Pindorama. Revista Brasileira de Ciência do Solo, Campinas, v.21, p.279-286, 1997.

CENTURION, J.F.; DEMATTÊ, J.L.I.; FERNANDES, F.M. Efeitos de sistemas de preparo nas propriedades químicas de um solo sob cerrado cultivado com soja. Revista Brasileira de Ciência do Solo, Campinas, v.9, p.267-270, 1985.

DE MARIA, I.C.; CASTRO, O.M. Fósforo, potássio e matéria orgânica em um latossolo roxo, sob sistemas de manejo com milho e soja. Revista Brasileira de Ciência do Solo, Campinas, v.17, p.471-477, 1993.

DICK,W.A.; ROSEBERG, R.J.; McCOY, E.L.; EDWARDS,W.M.; HAGHIRI, F. Surface hydrologic response of soils to no-tillage. Soil Science Society American Journal, Madison, v.53, p.1520-1526, 1989. 
EDWARDS, W.M.; NORTON, L.D.; REDMOND, C.E. Characterizing macropores that effect infiltration into nontilled soil. Soil Science Society American Journal, Madison, v.52, p.483-487, 1988 .

EMBRAPA. CENTRO NACIONAL DE PESQUISA DE SOLOS. Manual de métodos de análise de solo. 2.ed. Rio de Janeiro, 1997.212p.

GUERRA, J.G.M. Produção sazonal de Brachiaria Decumbens Stapf, conteúdo de fósforo orgânico e microbiano em solos tropicais de baixa fertilidade natural. 1993. 234f. Tese (Doutorado) - Universidade Federal Rural do Rio de Janeiro, Itaguaí.

GUERRA, J.G.M.; ALMEIDA, D.L. de; SANTOS, G.A.; FERNANDES, M.S. Conteúdo de fósforo orgânico em amostras de solos. Pesquisa Agropecuária Brasileira, Brasília, v.31, p.291-299, 1996.

ISENSEE, A.R.; SADEGUI, A.M. Effect of tillage reversal on herbicide leaching to groundwater. Soil Science, Baltimore, v.161, p.382-389, 1996

ISENSEE, A.R.; SADEGUI, A.M. Impact of tillage practice on runoff and pesticide transport. Journal Soil and Water Conservation, Ambeny, v.48, p.523-527, 1993.

MARTINS FILHO, E.C.; SILVA, J.R.C. Comparação de métodos de avaliação da erodibilidade em Latossolo VermelhoAmarelo distrófico. Revista Brasileira de Ciência do Solo, Campinas, v.9, p.75-178, 1985.

MOURA FERREIRA, P.H. Princípios de manejo e de conservação do solo. 3.ed. São Paulo: Nobel, 1986. 135p.

MUZILLI, O. Influência do sistema de plantio direto comparado ao convencional, sobre a fertilidade da camada arável do solo. Revista Brasileira de Ciência do Solo, Campinas, v.7, p.95-102, 1983.

NOVAIS, R.F.; BAHIA FILHO, A.F.C.; RIBEIRO, A.C.; VASCONCELOS, C.A. Solubilização de fosfatos incubados com amostras de latossolo submetidas a diferentes números de revolvimento. Revista Brasileira de Ciência do Solo, Campinas, v.9, p.23-26, 1985.
NÚÑEZ, J.E.V; AMARAL SOBRINHO, N.M.B.; PALMIERI, F.; MESQUITA, A.A. Conseqüências de diferentes sistemas de preparo do solo sobre a contaminação do solo, sedimentos e água por metais pesados. Revista Brasileira de Ciência do Solo, Campinas, v.23, p.981-990, 1999.

RESENDE, M.; KER, J.C.; BAHIA FILHO, A.F.C. Desenvolvimento sustentado do Cerrado. In: ALVAREZ,V.H.; FONTES, L.E.F. e FONTES, M.P.F. (Eds.) O solo nos grandes domínios morfoclimáticos do Brasil e o desenvolvimento sustentado. Viçosa: SBCS; UFV, DPS, 1996. p.169-200.

SHARPLEY, A.N.; MENZEL, R.G. The impact of soil and fertilizer phosphorus on the environment. Advance in Agronomy, San Diego v.41, p.297-324, 1987.

SILVA, M.L.N.; FREITAS, P.L.; BLANCANEAUX, P.; CURI, N; LIMA, J.M. Relação entre parâmetros da chuva e perdas de solo e determinação da erodibilidade de um Latossolo Vermelho-Escuro em Goiânia (GO). Revista Brasileira de Ciência do Solo, Campinas, v.21, p.131-137, 1997.

SILVA, G.N.;VIDOR, C. As práticas de manejo de solo na população microbiana. Revista Brasileira de Ciência do Solo, Campinas, v.8, p.291-296, 1984.

SPOSITO, G. The chemistry of soils. New York: Oxford University Press, 1989. 234p.

TEDESCO, M.J.; GIANELLO, C.; BISSANI, C.A.; BOHNEN, H.; VOLKWEISS, S.J. Análise de solo, plantas e outros materiais. 2.ed. Revisada e ampliada. Porto Alegre: Departamento de Solos, Faculdade de Agronomia, UFRGS, 1997. 174p. 